\title{
Safety of endoscopic mucosal resection (EMR) of large non-pedunculated colorectal adenomas in the elderly
}

\author{
K. Bronsgeest ${ }^{1}$ - J. F. Huisman ${ }^{2}$ - A. Langers ${ }^{1}$ - J. J. Boonstra ${ }^{1}$ - B. E. Schenk ${ }^{2}$. \\ W. H. de Vos tot Nederveen Cappel $^{2}$ • H. F. A. Vasen ${ }^{1}$ - J. C. H. Hardwick ${ }^{1}$
}

Accepted: 13 April 2017 / Published online: 8 September 2017

(C) The Author(s) 2017. This article is an open access publication

\begin{abstract}
Background Endoscopic mucosal resection (EMR) has been proven to be safe and effective for the treatment of colorectal adenomas. However, data are limited on the safety of this technique for large polyps and in elderly patients. Aims of our study were to examine the bleeding and perforation rates in patients with large non-pedunculated adenomas $(\geq 20 \mathrm{~mm})$ and to evaluate the influence of size $(\geq 40 \mathrm{~mm})$ and age $(\geq 75$ years) on the complication rates.

Methods In this multicenter retrospective study, patients who underwent EMR of non-pedunculated adenomas $\geq 20 \mathrm{~mm}$ between January 2012 and March 2016 were included. The demographics of the patients, the use of antithrombotic drugs, size of the polyps, type of resection, pathology report, occurrence of post-polypectomy bleeding, and perforation- and recurrence rate were collected.

Results In 343 patients, 412 adenomas were removed. Eighty patients (23.3\%) were $\geq 75$ years of age, 138 polyps (33.5\%) were $\geq 40 \mathrm{~mm}$. Bleeding complications were observed in 28 cases $(6.8 \%)$ and were found significantly more frequent in adenomas $\geq 40 \mathrm{~mm}$, independent of the use of antithrombotic therapy. Five perforations $(1.2 \%)$ were described, not related to the size of the polyp. There was no significant difference in complication rates between patients $<75$ years and patients
\end{abstract}

K. Bronsgeest and J. F. Huisman contributed equally to this work.

J. C. H. Hardwick

J.C.H.Hardwick@lumc.nl

1 Department of Gastroenterology and Hepathology, Leiden University Medical Centre, Albinusdreef 2, 2333, ZA Leiden, The Netherlands

2 Department of Gastroenterology and Hepathology, Isala, Zwolle, The Netherlands $\geq 75$ years. Bleeding complications rates were significantly higher in patients receiving double antithrombotic therapy. Conclusion EMR is safe in elderly patients. EMR of adenomas of $\geq 40 \mathrm{~mm}$ was associated with more bleeding complications. Future studies should address how the bleeding rates can be reduced in these patients, especially in those who use double antithrombotic treatment.

Keywords Endoscopic mucosal resection · EMR · Colorectal adenomas · Non-pedunculated adenomas · Giant adenomas . Complications $\cdot$ Bleeding $\cdot$ Perforations $\cdot$ Elderly

\section{Introduction}

Colorectal cancer is the most commonly diagnosed cancer of the gastro-intestinal tract. It is the leading cause of overall cancer death in Western countries after lung cancer [1-7]. In 2012 in Europe, the incidence of colorectal cancer was 60 per 100.000 people, resulting in nearly half a million new cases per year. The mortality rate of 29 per 100.000 accounted for $12.2 \%$ of all cancer deaths. The incidence of colorectal cancer is increasing and it is expected to rise from 1.4 to 2.4 million cases annually worldwide by $2035[1,2]$.

In many countries, population screening programs for the detection of colorectal cancer have been implemented, usually starting at the age of 50 or 55 and continuing until the age of 75 [5-8]. Screening tests including fecal occult blood test (FOBT), sigmoidoscopy or colonoscopy are used to detect early stage colorectal cancer and are proven effective in reducing mortality and morbidity rates $[1,5-7]$. Such programs lead to the detection of an increasing number of patients with large adenomas [9]. Critics of the colorectal cancer screening programs point towards the lack of evidence for a decrease in overall mortality, possibly due to the advanced age and 
extensive comorbidity in those found with colorectal cancer. Detection and removal of large polyps in this frail patient group has the potential to lead to morbidity and mortality that could negate any positive effects of the screening [10]. To be able to balance the health benefits with the risks, more information as to the nature and extent of these risks in this subgroup is required.

For the removal of large non-pedunculated polyps, endoscopic mucosal resection (EMR) is the usual treatment, and is reported to be effective and safe [11-31]. However, in polyps of $\geq 20 \mathrm{~mm}$, piecemeal resection is often required which is associated with higher recurrence rates [11, 15-17, 20, 32, 33].

The prevalence and size of colorectal polyps increases with age, so an increasing number of patients over the age of 75 are likely to undergo EMR. Various studies have reported on the complication rate of endoscopic resection in nonpedunculated polyps $\geq 20 \mathrm{~mm}[11,14,19,27,28,34]$. However, information about the complication rate of endoscopic resection of giant polyps $(\geq 40 \mathrm{~mm})$ and in elderly patients ( $\geq 75$ years) is limited $[26,27,34,35]$. Therefore, aims of our study were to examine the bleeding and perforation rates of endoscopic polyp resection in patients with large $(\geq 20 \mathrm{~mm})$, non- pedunculated polyps and, in particular, to evaluate the influence of size ( $\geq 40 \mathrm{~mm}$ ) and age ( $\geq 75$ years) on the complication rates.

\section{Material and methods}

This multicentre retrospective cohort study was performed between January 2012 and March 2016. For this type of study, formal consent was not required. Patients who had undergone EMR for colorectal non-pedunculated polyps $\geq 20 \mathrm{~mm}$ in Leiden University Medical Centre (LUMC) and Isala in Zwolle were included. Pedunculated polyps and malignant appearing polyps which were biopsied and eventually not removed by EMR were excluded in this study. All procedures were performed by endoscopists who were accredited for the Dutch National Bowel Screening Program. In addition, each had performed at least 100 previous EMRs $\geq 2 \mathrm{~cm}$.

\section{Procedure and equipment}

According to the national guideline, anticoagulant therapy (e.g. marcoumar, acenocoumarol) was stopped 3-5 days before the procedure and restarted on the same day after the procedure $[36,37]$. The decision to interrupt the use of antiplatelet therapy (e.g. aspirin, clopidogrel, dypiridamol) was evaluated per patient and per type of therapy. Patients using double therapy were instructed to stop one of the antiplatelet drugs before the procedure, in accordance with the guidelines [36-38]. Aspirin could be continued. Double therapy was resumed the day after the procedure. Participants received bowel preparation consisting of picoprep or kleanprep. The mode of sedation was assessed per patient. Most frequently, endoscopic polyp resection was performed under conscious sedation with midazolam and fentanyl. In longer procedures, patients were sedated with propofol and remifentanyl under supervision of an anaesthetic nurse specialist.

Procedures were performed under carbon dioxide insufflation using Olympus CF-HQ190L colonoscopes. The size of the lesion was estimated by the endoscopist during colonoscopy before resection by placing an open biopsy forceps (8mm) next to the lesion. The standard inject-and-cut EMR technique was applied by injecting a solution of Voluven (Hydroxyethyl starch) plasma expander, indigo carmine and in some cases a low concentration of epinephrine (1:100.000) for mucosal lifting. Argon plasma coagulation (pulsed 2, $25 \mathrm{~W})$, adrenaline $(1: 10.000)$ or clips were used in the case of bleeding. If necessary, e.g. in the case of visible vessels, wounds were approximated by clips. APC was also used to treat residual tissue in case of incomplete resection. All patients were observed for at least one hour. After an uncomplicated procedure they were discharged on the same day, or occasionally after an overnight stay.

\section{Histology}

Adenomas containing $>75 \%$ villous architecture were defined as villous adenomas and those comprising $25-75 \%$ villous architecture as tubulovillous. Focally present high-grade dysplasia $(<10 \%)$ was considered as low-grade dysplasia.

\section{Complications}

Information on complications was obtained from patients' electronic patient records including nursing and endoscopy reports. Bleeding was defined as early $(<48 \mathrm{~h}$ after completion of procedure) and delayed ( $>48 \mathrm{~h}$ after completion of procedure). Bleeding was registered as a complication when resulting in hospital (re)admission, (re-)intervention and/or therapy (e.g. repeat endoscopy, coiling, blood transfusion or surgery). Clip placement, argon coagulation or adrenaline injection to control bleeding during the initial colonoscopy was not considered as a complication. Perforation was diagnosed either periprocedurally by the endoscopist or by an abdominal CT-scan. Minor damage to the muscle wall, which was managed with clips was not defined as a complication, neither was a (suspicion of) perforation that was directly treated during colonoscopy that did not result in hospital admission. If a complication occurred during the removal of multiple polyps in one session, further investigation was performed to assess which polyp caused the complication (bleeding/perforation). 


\section{Follow-up}

In all patients a control visit or telephone appointment was planned about a month after colonoscopy to discuss histopathologic outcomes and follow up. According to the Dutch guidelines for colonoscopy surveillance, the follow-up endoscopy interval depends on the histopathology report (architecture, extent of dysplasia/carcinoma and margin of specimen), the mode of removal (en bloc or piecemeal), the size and number of the adenomas and the location in the colon [39]. If there is uncertainty histologically about the completeness of polyp removal, a surveillance colonoscopy was scheduled 3-6 months later. During follow-up endoscopy, the scar was macroscopically examined and biopsies were taken only in case of a suspected lesion. Residual tissue was treated with cold snare, APC or EMR. In two cases the endoscopy reports and patient records were inconclusive as to whether residual tissue had been detected and were therefore reported as missing and not included in follow-up analysis. In all other cases this was clearly documented.

\section{Statistical analysis}

Data collection and statistical analysis were performed by means of descriptive statistics with IBM SPSS Statistics 23 and Microsoft Office Excel 2010. Fisher's exact test was used to compare categorical outcome variables. Differences were considered significant if the two-sided $P$-value was $<0.05$.

\section{Results}

\section{Study group}

EMR of lesions $\geq 20 \mathrm{~mm}$ was successfully performed in 343 patients (mean age of 67.4 (SD 8.3), male: $n=201,(58.6 \%)$ ). One hundred and three patients $(30.1 \%)$ used antithrombotic drugs; $15.2 \%$ antiplatelet drugs, $11.1 \%$ anticoagulants and $3.8 \%$ double antiplatelet therapy. In sixty-nine patients, multiple lesions $\geq 20 \mathrm{~mm}$ were removed, either in one or more sessions. Table 1 shows an overview of patient and lesion characteristics.

\section{Lesion characteristics}

A total of 412 lesions were reported, of which 138 (33.5\%) $\geq 40 \mathrm{~mm}$. The mean size of the resected polyps was $32,3 \mathrm{~mm}$ (SD $13 \mathrm{~mm})$. Two hundred and five $(50.2 \%)$ were sessile and $203(49.8 \%)$ were flat (missing $n=4)$. Most polyps $(81.3 \%)$ were resected piecemeal.
Table 1 Patient- and lesion characteristics

n $\%$

Patient characteristics

Number of patients

Mean age $( \pm \mathrm{SD})$

$\geq 75 \mathrm{yr}( \pm \mathrm{SD})$

343

Gender (male)

$67,4 \pm 8,3$

$80(23,3 \%)$

$201(58,6 \%)$

ASA classification

Missing $n=1$

I

$89(26,0 \%)$

II

$228(66,7 \%)$

III

$25(7,3 \%)$

Antithrombotic therapy

Missing $n=1$

Antiplatelet therapy

$103(30,1 \%)$

$52(15,2 \%)$

Anticoagulant therapy

$38(11,1 \%)$

Double therapy

$13(3,8 \%)$

Lesion characteristics

Number of lesions

412

Size

Mean $(\mathrm{mm} \pm \mathrm{SD})$

$32,3 \pm 13$

Median (mm, IQR (25;75))

30,0 IQR $(20,0 ; 40,0)$

20-40mm

$274(66,5 \%)$

$\geq 40 \mathrm{~mm}$

$138(33.5 \%)$

Location

Ileocecal valve

$11(2,7 \%)$

Cecum

$54(13,1 \%)$

Ascending colon

$84(20,4 \%)$

Hepatic flexure

$37(9,0 \%)$

Transverse colon

$51(12,4 \%)$

Splenic flexure

$26(6,3 \%)$

Descending colon

$13(3,2 \%)$

Sigmoid

$55(13,3 \%)$

Rectosigmoid

$15(3,6 \%)$

Rectum

$66(16,0 \%)$

Paris

Sessile (0-Is)

$205(50,2 \%)$

Flat (0-IIa, 0-IIb, 0-IIc)

$203(49,8 \%)$

Histology

Tubulair adenoma

$145(37,2 \%)$

Tubulovillous adenoma

$168(43,1 \%)$

Villous adenoma

$10(2,6 \%)$

Sessile serrated

$50(12,8 \%)$

Other

$17(4,4 \%)$

No dysplasia

$52(12,4 \%)$

Low-grade dysplasia

$301(73,1 \%)$

High-grade dysplasia

$30(7,3 \%)$

Intramucosal carcinoma

$11(2,7 \%)$

Invasive carcinoma
$18(4,4 \%)$ 
Table 2 Complications and follow-up

\begin{tabular}{ll}
\hline & $\mathbf{n}(\mathbf{\%})$ \\
\hline $\begin{array}{l}\text { Number of lesions } \\
\text { Technique }\end{array}$ & 412 \\
$\quad$ En bloc & $77(18,7 \%)$ \\
$\quad$ R0 resection & $15(20,8 \%)$ \\
Piecemeal & $335(81,3 \%)$ \\
Complications & \\
Total bleeding complications & $28(6,8 \%)$ \\
$\quad$ Early bleeding $<48 \mathrm{~h}$ & $19(4,6 \%)$ \\
$\quad$ Delayed bleeding $>48 \mathrm{~h}$ & $9(2,2 \%)$ \\
Perforations & $5(1,2 \%)$ \\
Surgery & $16(3,9 \%)$ \\
Follow-up & $292(70.9 \%)$ \\
Residual tissue & $55(18.8 \%)$ \\
$\quad$ Enbloc & $4(7.3 \%)$ \\
$\quad$ Piecemeal & $51(92.7 \%)$ \\
\hline
\end{tabular}

\section{Histology}

Of all 412 polyps, 145 lesions (37.2\%) were tubular adenomas, $158(43.1 \%)$ were tubulovillous adenomas, 10 (2.6\%) were villous adenomas and $50(12.8 \%)$ were sessile serrated polyps. In 22 cases, growth patterns were not described in the histology reports. Low grade dysplasia was the most common pathology comprising 301 cases $(73.1 \%) .11$ cases $(2.7 \%)$ showed an intramucosal carcinoma and 18 cases $(4.4 \%)$ an invasive adenocarcinoma. R0 resection was achieved in $20.8 \%$ of all en bloc resections.

\section{Complications}

Table 2 provides an overview of the complications per lesion in this study. Detailed results on complications are presented in Tables 3, 4, 5 and 6.

Total bleeding complication rate was $6.8 \%$ (28 cases) and occurred significantly more in polyps $\geq 40 \mathrm{~mm}$ compared to polyps $20-40 \mathrm{~mm}(10.9 \%$ vs. $4.7 \%, p=0.04)$. No significant difference was observed in antithrombotic drug use between polyps $20-40 \mathrm{~mm}$ and $\geq 40 \mathrm{~mm} \quad(p=0.252)$. Twice as many bleeding complications occurred when using antithrombotic therapy $(10.8 \%$ vs. $5.1 \%, p=0.051)$, especially double therapy $(31 \%, p=0.002)$ (Tables 5 and $6)$. No significant difference was observed in patients $<75$ years vs. patients $\geq 75$ years $(6.2 \%$ vs. $9.3 \%, p=0.33)$. There was one patient who had both an early and delayed bleeding.

Early bleeding < 48h: In 19/412 cases (4.6\%) early bleeding was reported. Thirteen of these nineteen cases underwent repeat colonoscopy; four cases needed additional blood transfusion. In the remaining six cases, no colonoscopy was performed. Two of these six patients received a blood transfusion and were sent for angiographic embolisation, the other four were managed conservatively. The mean hospital stay was 2.1 days (range $0-5$ days).

There was no significant elevated risk in early bleeding for polyps $\geq 40 \mathrm{~mm}$ compared to polyps $20-40 \mathrm{~mm}$ (6.5\% vs. $3.6 \% ; p=0.216)$ and for patients $\geq 75$ years compared to patients $<75$ years $(5.8 \%$ vs. $4.3 \%$; $p=0.565)$. The use of antithrombotics resulted in more early bleeding. However, the difference was not significant $(7.5 \%$ vs. $3.4 \% ; p=0.117$ ) (Table 5), and mainly due to double antithrombotic use $(p=0.004)$ (Table 6).

Delayed bleeding $>48 h$. In 9 of 412 lesions (2.2\%) patients were admitted to the hospital for delayed bleeding and all patients underwent repeat colonoscopy. Three cases required blood transfusion. No CT intervention was needed. The mean hospital stay was 1.9 days (range $0-4$ days).

Delayed bleeding occurred more in polyps $\geq 40 \mathrm{~mm}$ compared to polyps $20-40 \mathrm{~mm}(4.3 \%$ vs. $1.1 \% ; p=0.066)$, however this was not significant. No significant difference was found in delayed bleeding complications in patients $\geq 75$ years compared to patients $<75$ years. (3.5\% vs. $1.8 \% ; p=0.400$ ). Almost twice as many delayed bleeding complications occurred in patients using antithrombotic drugs compared to patients not using antithrombotic drugs (3.3\% vs. $1.7 \% ; p=0.293$ ), but this difference was not significant (Table 5).

Perforation Five (1.2\%) perforations occurred. One case was managed conservatively, and three cases were successfully closed with clips during the initial endoscopy. Surgical intervention was needed in one case.

Table 3 Complications versus polyp size and patients' age

\begin{tabular}{|c|c|c|c|c|c|c|}
\hline & $20-40 \mathrm{~mm}(n=274)$ & $\geq 40 \mathrm{~mm}(n=138)$ & $p$ value & $<75$ jr $(n=326)^{*}$ & $\geq 75 \mathrm{jr}(n=86)^{*}$ & $p$ value \\
\hline Total bleeding complications $(n=28)$ & $13(4.7 \%)$ & $15(10.9 \%)$ & 0,036 & $20(6.2 \%)$ & $8(9,3 \%)$ & 0,331 \\
\hline Early bleeding $(n=19)$ & $10(3,6 \%)$ & $9(6,5 \%)$ & 0,216 & $14(4,3 \%)$ & $5(5,8 \%)$ & 0,565 \\
\hline Delayed bleeding $(n=9)$ & $3(1.1 \%)$ & $6(4.3 \%)$ & 0,066 & $6(1.8 \%)$ & $3(3,5 \%)$ & 0,400 \\
\hline Perforation $(n=5)$ & $3(1,1 \%)$ & $2(1,4 \%)$ & 1,000 & $5(1,5 \%)$ & 0 & 0,588 \\
\hline
\end{tabular}

*evaluated per lesion 
Table 4 Antithrombotic therapy

in relation to polyp size

\begin{tabular}{llll}
\hline & $20-40 \mathrm{~mm}(n=274)$ & $\geq 40 \mathrm{~mm}(n=138)$ & $p$ value \\
\hline Antithrombotic therapy $^{*}(n=120)$ & $85(31,0 \%)$ & $35(25,4 \%)$ & 0,252 \\
No antithrombotic therapy* $(n=292)$ & $189(69,0 \%)$ & $103(74,6 \%)$ & \\
\hline
\end{tabular}

*evaluated per lesion

No significant difference in perforation rate was observed between resection of 20-40 $\mathrm{mm}$ and the resection of polyps larger than $40 \mathrm{~mm}(1.1 \%$ vs. $1.4 \%, p=1.000)$. No perforations occurred in elderly patents above the age of $75(1.5 \%$ vs. $0 \%$, $p=0.588$ ).

Other complications In total, three complications were observed. One patient was admitted for observation after possible aspiration at the end of a colonoscopy under propofol sedation. She was discharged the next day with oral antibiotics without further complications. Another patient was observed after having a post procedural epileptic insult after discharge. Midazolam/fentanyl was used during endoscopy. Lastly, one patient experienced a painless pneumoscrotum directly after the procedure using propofol without further complications.. To the best of our knowledge, no cardiovascular events occurred and no deaths related to colonoscopy were observed.

\section{Surgery}

Surgical resection after polypectomy was performed in 16 cases $(3.9 \%)$. In one patient, surgical intervention was performed because of a perforation during endoscopy. In 15 of these 16 cases, additional surgical resection was performed because of malignant histology of the resected polyp. In five of these fifteen cases, residual carcinoma was found in the surgical specimen. In nine of the fifteen cases, no malignancy was found. One case was lost to follow up as the patient underwent surgery in another hospital.

\section{Follow-up data}

In 292 out of $412(70.9 \%)$ cases, a follow-up colonoscopy was performed with a mean follow-up time of 6.94 months (SD 5.94 months, $95 \%$ CI 6.26-7.63 months).
The remaining cases included patients either awaiting a first follow-up procedure $(n=61)$, patients without indication for surveillance (e.g. comorbidity, advanced age, or colon resection $(n=41)$ ), patients lost to follow-up $(n=9)$ or patients refusing follow-up ( $n=9$ ).

Assessment of polyp removal sites mostly occurred by macroscopic examination of the scar. Residual tissue/ recurrence was found in 55/292 (18.8\%) lesions, and was treated with snare or APC. Most residual tissue was found after piecemeal removal, in 51/55 cases $(92.7 \%, p<0.05)$.

\section{Discussion}

The present study supports the premise that EMR of large non-pedunculated polyps is safe in elderly ( $\geq 75$ years) patients. EMR of giant adenomas $(\geq 40 \mathrm{~mm})$ is associated with more bleeding complications but did not lead to more perforations.

Various studies have reported on complication rates after EMR. However, information about the complication rate of EMR of giant polyps and EMR in elderly patients is limited $[26,27,34,35]$. Our retrospective study evaluated the outcomes and safety of EMR in a large cohort of patients who underwent EMR of polyps $\geq 20 \mathrm{~mm}$. A quarter of the study group were 75 years or older and one third had lesions of more than $40 \mathrm{~mm}$.

The overall complication rates observed in our patients were within the range reported in the literature; early bleeding $0-7.9 \%$ and delayed bleeding $0-2.3 \%[11,14,19,27,28,34$, 40]. We did not observe any deaths due to the interventions. Some studies have reported increased complication rates (bleeding and perforations) of endoscopic removal of larger lesions $\geq 30 \mathrm{~mm}[12,23,26,35]$. The perforation rate of our study in patients with polyps $\geq 40 \mathrm{~mm}$ was similar to the perforation rate in patients with polyps of $20-40 \mathrm{~mm}$. These findings are in agreement with the study by Luigiano et al. [27] On
Table 5 Bleeding complications in antithrombotic therapy

\begin{tabular}{llll}
\hline & $\begin{array}{l}\text { Antithrombotic } \\
\text { therapy }^{*}(n=120)\end{array}$ & $\begin{array}{l}\text { No antithrombotic } \\
\text { therapy* }(n=292)\end{array}$ & $p$ value \\
\hline $\begin{array}{c}\text { Total bleeding complications }(n=28) \\
\text { Early bleeding }(n=19)\end{array}$ & $13(10.8 \%)$ & $15(5,8 \%)$ & 0,051 \\
Delayed bleeding $(n=9)$ & $9(7,5 \%)$ & $10(3,4 \%)$ & 0,117 \\
\hline
\end{tabular}

*evaluated per lesion 
Table 6 Bleeding complications in antithrombotic therapy, subdivided into different therapies

\begin{tabular}{|c|c|c|c|c|c|c|}
\hline & \multicolumn{2}{|c|}{ Antiplatelets $(n=57)$} & \multicolumn{2}{|c|}{ Coumarins $(n=47)$} & \multicolumn{2}{|c|}{ Double therapy* $(n=16)$} \\
\hline & $n$ & $p$ value & $n$ & $p$ value & $n$ & $p$ value \\
\hline Total bleeding ( $n=13)$ & 4 & 0,511 & 4 & 0,293 & 5 & 0,002 \\
\hline Early bleeding $(n=9)$ & 3 & 0,454 & 2 & 0,677 & 4 & 0,004 \\
\hline Delayed bleeding $(n=4)$ & 1 & 1,000 & 2 & 0,252 & 1 & 0,304 \\
\hline
\end{tabular}

*antiplatelet drugs the other hand, we found a significantly higher total bleeding complication rate in polyps larger than $40 \mathrm{~mm}$ compared to 20 $40 \mathrm{~mm}$ polyps. This finding could not be explained by differences in antithrombotic drug use between both groups. Sahwney et al. have also reported lesion size as an independent predictive factor of post polypectomy bleeding [41].

In elderly patients ( $\geq 75$ years) we did not find significantly more bleeding complications. Also, no perforations were observed in these patients. Gómez et al. evaluated the outcomes and safety of colorectal EMR in patients older than 80 years [34]. They reported a total bleeding rate of $2.3 \%$, and a perforation rate of $3 \%$. The authors concluded that EMR for the removal of polyps $\geq 20 \mathrm{~mm}$ in elderly patients is safe.

Overall bleeding complications were more frequently observed when antithrombotic drugs were used (borderline significant $=0.051$ ), in particular, in patients who used double antiplatelet therapy $(P<0.05)$. Guidelines on endoscopy in patients with antithrombotic therapy advise to stop one of antiplatelet drugs when using double therapy 5-7 days before the procedure [36-38]. The other drug can be continued, which is mainly aspirin. Less is known regarding timing of reinitiation of the antiplatelet drug [38]. The drug is restarted the day after the procedure, according to the guidelines $[37,38]$. Based on our results we would recommend to consider postponement of restarting the antiplatelet drug after the procedure as we observed significantly more early bleeding complications in patients using double therapy. Numbers are however small and future prospective studies should reveal after how many days the risk of bleeding has reduced after large EMR.

Residual tissue or recurrence was observed in $18.8 \%$, which is within the range reported in literature (4.2-40\%) [11, 14, 19, 27, 28, 34]. However, our percentage might be an underestimate because scars were not routinely biopsied. Most residual tissue was found, as expected, after piecemeal removal.

This study adds significantly to the existing literature due to its large size, the high proportion of elderly people and the large number of giant adenomas. A further positive aspect is that we were fully informed about the occurrence of complications after polypectomy. The limitations of our study are its retrospective design and lack of routine biopsies of the polypectomy site at the follow-up colonoscopies.
In conclusion, the implementation of screening programs worldwide has led to the detection of increasing numbers of large non-pedunculated adenomas, often in elderly patients. This number is likely to increase further due to population ageing and higher life expectancy. Since surgical removal of giant adenomas at an advanced age is associated with a substantial mortality (5\%), endoscopical removal is increasingly performed [42]. Our study showed that EMR is a safe procedure for both elderly patients above age of 75 and for nonpedunculated colorectal polyps larger than $40 \mathrm{~mm}$, although it is associated with significant morbidity, largely due to bleeding. Improved methods are needed to reduce post polypectomy bleeding in patients that use antithrombotic treatments and with giant $(\geq 40 \mathrm{~mm})$ polyps.

Financial conflicts This study was not funded.

\section{Compliance with ethical standards}

Informed consent For this type of study, formal consent is not required.

Conflict of interest The authors declare that they have no conflict of interest.

Open Access This article is distributed under the terms of the Creative Commons Attribution 4.0 International License (http:// creativecommons.org/licenses/by/4.0/), which permits unrestricted use, distribution, and reproduction in any medium, provided you give appropriate credit to the original author(s) and the source, provide a link to the Creative Commons license, and indicate if changes were made.

\section{References}

1. Dušek L et al, Epidemiology of colorectal cancer: international comparison http://www.crcprevention.eu/index.php?pg= colorectal-cancer-epidemiology. Accessed 12 Mar 2016

2. International WCRF, Colorectal cancer statistics. http://www.wcrf. org/int/cancer-facts-figures/data-specific-cancers/colorectalcancer-statistics. Accessed 12 Mar 2016

3. Doubeni C, Tests for screening for colorectal cancer: Stool tests, radiologic imaging and endoscopy. https:/www.uptodate.com/ contents/tests-for-screening-for-colorectal-cancer-stool-testsradiologic-imaging-and-endoscopy. Accessed 12 Mar 2016

4. CBS, Overledenen; belangrijke doodsoorzaken (korte lijst), leeftijd, geslacht. http://statline.cbs.nl/StatWeb/publication/?VW=T\&DM= SLNL\&PA=7052_95\&. Accessed 12 Mar 2016 
5. Zavoral $\mathrm{M}$ et al (2009) Colorectal cancer screening in Europe. World J Gastroenterol 15(47):5907-5915

6. Winawer S et al, World Gastroenterology Organisation/ International Digestive Cancer Alliance Practice Guidelines: Colorectal cancer screening http://www.worldgastroenterology. org/UserFiles/file/guidelines/colorectal-cancer-screening-english2007.pdf. Accessed 12 Mar 2016

7. Labianca R et al (2013) Early colon cancer: ESMO Clinical Practice Guidelines for diagnosis, treatment and follow-up. Ann Oncol 24(Suppl 6):vi64-vi72

8. Doubeni $\mathrm{C}$, Screening for colorectal cancer: Strategies in patients at average risk. https://www.uptodate.com/contents/screening-forcolorectal-cancer-strategies-in-patients-at-average-risk. Accessed 12 Mar 2016

9. van Erp SJ et al (2016) Identification of familial colorectal cancer and hereditary colorectal cancer syndromes through the Dutch population-screening program: results ofa pilot study. Scand J Gastroenterol 51(10):1227-1232

10. Shaukat A et al (2013) Long-term mortality after screening for colorectal cancer. N Engl J Med 369(12):1106-1114

11. Pellise $\mathrm{M}$ et al (2016) Endoscopic mucosal resection for large serrated lesions in comparison with adenomas: a prospective multicentre study of 2000 lesions. Gut 66(4):644-653

12. Seidel $\mathrm{J}$ et al (2016) Complication and local recurrence rate after endoscopic resection of large high-risk colorectal adenomas of $>/=3 \mathrm{~cm}$ in size. Int J Color Dis 31(3):603-611

13. Rao AK et al (2016) Large sessile serrated polyps can be safely and effectively removed by endoscopic mucosal resection. Clin Gastroenterol Hepatol 14(4):568-574

14. Knabe $\mathrm{M}$ et al (2014) Standardized long-term follow-up after endoscopic resection of large, nonpedunculated colorectal lesions: a prospective two-center study. Am J Gastroenterol 109(2):183-189

15. Cipolletta L et al (2014) Endoscopic resection for superficial colorectal neoplasia in Italy: a prospective multicentre study. Dig Liver Dis 46(2):146-151

16. Woodward TA et al (2012) Predictors of complete endoscopic mucosal resection of flat and depressed gastrointestinal neoplasia of the colon. Am J Gastroenterol 107(5):650-654

17. Santos CE, Malaman D, Pereira-Lima JC (2011) Endoscopic mucosal resection in colorectal lesion: a safe and effective procedure even in lesions larger than $2 \mathrm{~cm}$ and in carcinomas. Arq Gastroenterol 48(4):242-247

18. Othman MO, Wallace MB (2011) Endoscopic mucosal resection (EMR) and endoscopic submucosal dissection (ESD) in 2011, a western perspective. Clin Res Hepatol Gastroenterol 35(4):288-294

19. Moss A et al (2011) Endoscopic mucosal resection outcomes and prediction of submucosal cancer from advanced colonic mucosal neoplasia. Gastroenterology 140(7):1909-1918

20. Mannath J et al (2011) Polyp recurrence after endoscopic mucosal resection of sessile and flat colonic adenomas. Dig Dis Sci 56(8): 2389-2395

21. Lim TR et al (2010) Endoscopic mucosal resection of colorectal polyps in typical UK hospitals. World J Gastroenterol 16(42):53245328

22. Ahlawat SK et al (2011) Large colorectal polyps: endoscopic management and rate of malignancy: does size matter? J Clin Gastroenterol 45(4):347-354

23. Hochdorffer R et al (2010) Endoscopic resection of "giant" colorectal lesions: long-term outcome and safety. Z Gastroenterol 48(7): $741-747$
24. Dell'Abate P et al (2001) Endoscopic treatment of colorectal benign-appearing lesions $3 \mathrm{~cm}$ or larger: techniques and outcome. Dis Colon rectum 44(1):112-118

25. Ferrara F et al (2010) Efficacy, safety and outcomes of 'inject and cut' endoscopic mucosal resection for large sessile and flat colorectal polyps. Digestion 82(4):213-220

26. Ah Soune P et al (2010) Large endoscopic mucosal resection for colorectal tumors exceeding $4 \mathrm{~cm}$. World J Gastroenterol 16(5): 588-595

27. Luigiano C et al (2009) Endoscopic mucosal resection for large and giant sessile and flat colorectal polyps: a singlecenter experience with long-term follow-up. Endoscopy 41(10):829-835

28. Arebi $\mathrm{N}$ et al (2007) Endoscopic mucosal resection of 161 cases of large sessile or flat colorectal polyps. Scand J Gastroenterol 42(7): 859-866

29. Jameel JK et al (2006) Endoscopic mucosal resection (EMR) in the management of large colo-rectal polyps. Color Dis 8(6):497-500

30. Conio $\mathrm{M}$ et al (2004) EMR of large sessile colorectal polyps. Gastrointest Endosc 60(2):234-241

31. Chen WC, Wallace MB (2016) Endoscopic management of mucosal lesions in the gastrointestinal tract. Expert Rev Gastroenterol Hepatol 10(4):481-495

32. Ortiz AM et al (2014) Endoscopic mucosal resection recurrence rate for colorectal lesions. South Med J 107(10):615-621

33. Belderbos TD et al (2014) Local recurrence after endoscopic mucosal resection of nonpedunculated colorectal lesions: systematic review and meta-analysis. Endoscopy 46(5):388-402

34. Gomez V et al (2014) Colonic endoscopic mucosal resection of large polyps: is it safe in the very elderly? Dig Liver Dis 46(8): 701-705

35. Consolo P et al (2010) Endoscopic resection as a safe and effective technique for treatment of pedunculated and non-pedunculated benign-appearing colorectal neoplasms measuring $40 \mathrm{~mm}$ or more in size. Minerva Med 101(5):311-318

36. ten Cate H, van Heukelem HA, Richtlijn NGMDL. Endoscopische ingrepen bij patiënten met antistolling of plaatjesaggregatieremming. https://www.msbi.nl/promise/ LinkClick.aspx ?fileticket $=i K 1 M Q K W u q d c \% 3 D \&$ tabid= $129 \&$ portalid $=0 \&$ mid $=595$. Accessed 12 Mar 2016

37. NVMDL (2016) Nederlandse Richtlijn Beleid antitrombotische therapie rondom endoscopische procedures. http://www.mdl.nl/ uploads/240/1905/Richtlijn_antitrombotische_therapie_final_mei_ 2016.pdf. Accessed 12 Oct 2016

38. Acosta RD et al (2016) The management of antithrombotic agents for patients undergoing GI endoscopy. Gastrointest Endosc 83(1): $3-16$

39. Dekker EE et al, Nederlandse Richtlijn Coloscopie Surveillance. http://www.mdl.nl/uploads/240/1308/Richtlijn_Coloscopie_ Surveillance definitief_2013.pdf. Accessed 12 Mar 2016

40. Carvalho R et al (2013) Endoscopic mucosal resection of large colorectal polyps: prospective evaluation of recurrence and complications. Acta Gastroenterol Belg 76(2):225-230

41. Sawhney MS et al (2008) Risk factors for severe delayed postpolypectomy bleeding. Endoscopy 40(2):115-119

42. McNicol L et al (2007) Postoperative complications and mortality in older patients having non-cardiac surgery at three Melbourne teaching hospitals. Med J Aust 186(9):447-452 